\title{
Fabrication and Evaluation of Taste Masked Resinate of Risperidone and Its Orally Disintegrating Tablets
}

\author{
Dali Shukla, Subhashis Chakraborty, Sanjay Singh, and Brahmeshwar Mishra* \\ Department of Pharmaceutics, Institute of Technology, Banaras Hindu University; Varanasi-221 005, India. \\ Received November 6, 2008; accepted January 5, 2009; published online January 13, 2009
}

\begin{abstract}
The present investigation was undertaken to design a simple, rapid, cost effective and highly efficient process to fabricate a tasteless complex of risperidone using ion exchange resin (IER), evaluate the molecular properties of the resinate and finally incorporate it into orally disintegrating tablets (ODT). The resinate formation using Amberlite IRP64, was confirmed using the characterization methods: Fourier transform-infrared (FTIR), X-ray diffraction (XRD) and differential scanning calorimetry (DSC). The maximum loading efficiency achieved was $99.72 \pm 0.16 \%$ in $1: 4$ (drug : resin weight) ratio at $\mathrm{pH} 6.0$, temperature at $22^{\circ} \mathrm{C}$ in a period of $1.5 \mathrm{~h}$ using ethanol: water $(1: 1, \mathrm{v} / \mathrm{v})$ as the complexation medium. The complex was compressed into orally disintegrating tablet. The drug release from the complex was about $2.5 \%$ in $120 \mathrm{~s}$ in $5 \mathrm{ml}$ of $\mathrm{pH} 6.8$ phosphate buffer which has been used to mimic the salivary fluid volume and pH. Dissolution studies using $500 \mathrm{ml}$ of $0.1 \mathrm{~N} \mathrm{HCl}$ at $50 \mathrm{rpm}$ in USP Apparatus II released $92 \%$ in $5 \mathrm{~min}$, indicating complete drug release from the complex in the stomach. Resinate was tasteless while the fabricated ODTs were pleasantly tasting without any bitterness of drug as confirmed by the taste panel.
\end{abstract}

Key words risperidone; ion exchange resin; resinate; bitter taste; orally disintegrating tablet

The production of a palatable dosage form is very important for patient compliance, which in turn decides the commercial success of the product. The masking of unpleasant taste in orally-disintegrating tablets and chewable tablets is therefore an important consideration in the formulation of many therapeutic agents and is achieved by minimizing direct contact between the active species and the taste receptors in the buccal cavity of the subject. In order to improve the palatability of a pharmaceutical product, many techniques have been developed, which have not only improved the taste, but also the stability of the drug in the formulation and performance of the product. Use of ion exchange is one of the methods for taste masking.

Ion Exchange Resins (IERs) for Taste Masking Ion exchange (IE) involves the reversible interchange of ions (of like charge) between a liquid and a solid phase, with no radical change in the structure and properties of the solid. ${ }^{1)}$ IERs are high molecular weight polymers and most frequently employed polymeric network is a copolymer of styrene and divinylbenzene. They have wide applications in enhancing the stability of sensitive drugs, sustaining the release of drug, ${ }^{2)}$ as disintegrating agents and for masking the bitter taste of drug. ${ }^{3)}$ Drug binding to the resin can be achieved by two processes. First approach is repeated elution of drug solution through a column of swollen activated resin bead where drug is allowed to interact with binding sites of resin and second is by prolonged contact of resin with the drug solution. ${ }^{4-7)}$ Drug molecules get adsorbed on the IER, resulting in the formation of an insoluble adsorbate or resinate by forming weak ionic bonds which does not dissociate under the salivary $\mathrm{pH}$ conditions, hence, masks the unpleasant taste of drugs.

After administration of resinate, the release of drug from the resin depends on the properties of the resin and the ionic environment within the gastrointestinal tract (GIT). Drug molecules get released from resin by exchanging with appropriately charged ions in the GIT and free drug is available for absorption. ${ }^{8)}$ The IER devoid of drug is eliminated or biodegraded from or at the site of delivery. ${ }^{9)}$
Depending on nature of monomer and their ionic strength, IER can be classified into four major classes: strong acid cation exchange (CE) resin, weak acid CE resin, strong base anion exchange (AE) resin and weak base AE resin. Strong acid $\mathrm{CE}$ resins constituted of sulfonated styrene divinylbenzene copolymer are functional throughout the entire $\mathrm{pH}$ range and weak acid $\mathrm{CE}$ resins function at $\mathrm{pH}$ values above 6.0. Both can be used for masking the taste of basic drugs. Similarly, strong base AE resins are functional throughout the entire $\mathrm{pH}$ range, while the weak base $\mathrm{AE}$ resins function well below $\mathrm{pH} 7.0{ }^{10)}$ These can be used for masking the taste of acidic drugs.

Application of IER for masking the bitter taste of drugs has been explored in many investigations. Oral suspension of quinolones (orbifloxacin) and/or their derivatives are prepared by IE process using methacrylic acid polymer cross linked with divinylbenzene, as the carrier. The resinate formation eliminates the extreme bitterness of the quinolones. This resinate can be suspended into suitable vehicles with flavoring agents, anticaking agent and a preservative (sorbic acid) resulting in the formulation of a palatable oral liquid dosage for. ${ }^{11)}$ Amberlite IRP-69, a CE resin, is reported to mask the bitter taste of buflomedil. ${ }^{12)}$ For a conditioned taste aversion (CTA) agent to be successful in wildlife management applications, the compound must not be detectable by the animal. Levamisole is an effective CTA agent when administered by oral intubation, but it is readily detected by a number of species when mixed directly in food. Two different resins i.e. Amberlite ${ }^{\circledR}$ IRP-64 and Amberlite ${ }^{\circledR}$ IRP-69 were used for taste masking of levamisole and release studies indicated that the resinate formed using IRP-64 resin would be most suitable for use in wildlife management. ${ }^{13)}$ Betty et $a l$. have patented a mixture of coated and uncoated sulfonic acid resins loaded with dextromethorphan for taste masking and sustained release. ${ }^{2)}$ Polystyrene matrix CE resins have been used for masking the bitter taste of chlorpheniramine maleate, diphenhydramine $\mathrm{HCl}$, ephedrine $\mathrm{HCl}$, noscapine $\mathrm{HCl}$, and amphetamine sulphate. ${ }^{14)}$ Bitter taste of erythromy- 
cin and clarithromycin was significantly reduced by adsorption on Carbopol 934. Taste masking was further improved by encapsulating the adsorbate particles with polymer coatings. Hydroxypropyl methylcellulose phthalate (HPMCP-55) provided the best combination of taste making, suspension stability and bioavailability. ${ }^{15)}$

In the present investigation, an attempt has been made to fabricate a non friable taste masked orally disintegrating tablets (ODT) of an intensely bitter tasting antipsychotic drug risperidone, using a simple, rapid and cost effective process with equivalent efficiency to that of the previously reported lyophilized product. ${ }^{16)}$ The molecular properties of resinate produced for taste making purpose was evaluated using X-ray diffraction (XRD), Fourier transform-infrared (FT-IR) and differential scanning calorimetry (DSC), and finally the resinate was incorporated into ODT.

\section{Experimental}

Materials Risperidone was a kind gift from Jubilant Organosys Ltd., Noida, India. Polacrilex IER (Amberlite IRP64) was procured from Rohm and Haas Company, Philadelphia, PA, U.S.A., mannitol (Pearlitol SD 200) from Roquette America Inc., Keokuk, IA, U.S.A., crospovidone (Polyplasdone XL-10) from ISP, Hyderabad, India, aspartame from Ajinomoto Co., Inc., Tokyo, Japan, colloidal silicone dioxide (Aerosil 200) from Degussa AG, Frankfurt, Germany, calcium stearate from BASF Corporation, U.S.A./Germany, taste masking flavor from Fermenich Aromatics (India) Pvt. Ltd., Mumbai, India, strawberry and peppermint flavor from Givaudan (India) Pvt. Ltd., Mumbai, India. Risperdal ${ }^{\mathbb{B}} \mathrm{M}-\mathrm{TAB}^{\mathrm{TM}}$ Orally Disintegrating Tablets $4 \mathrm{mg}$ (marketed product) was of Janssen Pharmaceutica Products, L.P., Titusville, NJ, U.S.A. Other chemicals used were of analytical grade and were purchased locally.

Risperidone Resinate Formation. Pretreatment of Resin One hundred grams of resin was purified by washing with $200 \mathrm{ml}$ ethanol followed by $200 \mathrm{ml}$ ethanol water mixture $(1: 1)$ and finally washing with $200 \mathrm{ml}$ of water to remove all the impurities. The resin was then dried in vacuum oven at $60{ }^{\circ} \mathrm{C}$ till the moisture content came below $5 \%$ which was checked by Karl Fisher instrument. ${ }^{17}$

Effect of Risperidone Resin Ratio on Drug Loading Resinate can be obtained by two methods, batch method and column method. ${ }^{18)}$ The batch process was preferred as the fine particles of Amberlite IRP64 resin (particle size $<150 \mu \mathrm{m})^{19)}$ would get washed away from conventional columnar process which is normally used for large size ion exchange resins. Accurately weighed, $0.25,0.50,0.75,1.0,1.25,1.50,1.75$ and $2.0 \mathrm{~g}$ of pretreated resin was placed in a series of $100 \mathrm{ml}$ volumetric flasks containing $25 \mathrm{ml}$ of deionized water and was allowed to swell for $45 \mathrm{~min}$. Two-hundred and fifty milligrams of risperidone was accurately weighed and was added to all the flasks, to obtain $1: 1,1: 2,1: 3,1: 4,1: 5,1: 6,1: 7$ and $1: 8$, drug: resin ratio, with further addition of $25 \mathrm{ml}$ of deionized water and was stirred for $48 \mathrm{~h}$ on a mechanical shaker to allow maximum possible loading. Five milliliters of methanol was added to dissolve unloaded drug, the mixture was filtered immediately by vacuum filtration and the residue was washed with $200 \mathrm{ml}$ of deionized water. Finally, the unbound drug in filtrate was estimated by UV spectrophotometry at $238 \mathrm{~nm}$ and drug-loading efficiency was calculated. The prepared resinate was dried in vacuum oven at $60^{\circ} \mathrm{C}$ till the moisture content was below $5 \%$ (the post loading procedure, estimation and the final resinate drying is common in the further investigation, wherever applicable)

A control experiment was performed in which $250 \mathrm{mg}$ of risperidone was added to $100 \mathrm{ml}$ volumetric flask containing $50 \mathrm{ml}$ of deionized water and was shaken on mechanical shaker for $48 \mathrm{~h}$. After that $5 \mathrm{ml}$ of methanol was added and the suspension was filtered immediately and the drug content was estimated as mentioned earlier.

Effect of pH on Drug Loading Buffer solutions of different $\mathrm{pH}$ ranging from 4.0 to 8.0 were prepared as per U.S. pharmacopoeia (USP) specifications. One gram of pretreated resin was placed in a series of $100 \mathrm{ml}$ volumetric flasks containing $25 \mathrm{ml}$ of buffer solution of $\mathrm{pH} 4.0,5.0,5.5,6.0,6.5$, 7, 7.5 and 8.0 respectively and allowed the resin to swell for $45 \mathrm{~min}$. Twohundred and fifty milligrams of risperidone was accurately weighed to get $1: 4$ ratios and was added to every flask, with further addition of $25 \mathrm{ml}$ of respective buffer solutions and was stirred for $48 \mathrm{~h}$ on a mechanical shaker to allow maximum possible loading. Further, steps have been carried out simi- larly as mentioned under heading 'Effect of risperidone resin ratio on drug loading.'

Effect of Aqueous Alcoholic Medium on Drug Loading One gram of pretreated resin was placed in $100 \mathrm{ml}$ volumetric flasks containing $25 \mathrm{ml}$ of deionized water and was allowed to swell for $45 \mathrm{~min}$. Two-hundred and fifty milligrams of risperidone was accurately weighed and was added to the flask, with further addition of $25 \mathrm{ml}$ of ethanol and stirred for $48 \mathrm{~h}$ on a mechanical shaker to allow maximum possible loading. The suspension was filtered and the residue was washed with $200 \mathrm{ml}$ of deionized water. Unbound drug in filtrate was estimated spectrophotometrically at $238 \mathrm{~nm}$ and drugloading efficiency was calculated.

Effect of Exposure Time on Drug Loading One gram of pretreated resin was placed in a series of $100 \mathrm{ml}$ volumetric flasks containing $25 \mathrm{ml}$ of deionized water and was allowed to swell for $45 \mathrm{~min}$. Two-hundred and fifty milligrams of risperidone was accurately weighed and was added with further addition of $25 \mathrm{ml}$ of deionized water and was stirred for $30 \mathrm{~min}, 1 \mathrm{~h}$, $1.5 \mathrm{~h}, 2 \mathrm{~h}, 4 \mathrm{~h}$ and $6 \mathrm{~h}$, respectively, on a mechanical shaker to allow loading. Further steps have been carried out similarly as mentioned under heading 'Effect of risperidone resin ratio on drug loading.' Similar procedure was also carried out for aqueous alcoholic medium as given in previous experiment of this medium with stirring time of $30 \mathrm{~min}, 1 \mathrm{~h}, 1.5 \mathrm{~h}, 2 \mathrm{~h}, 4 \mathrm{~h}$ and $6 \mathrm{~h}$.

Effect of Temperature on Drug Loading One gram of pretreated resin was placed in a series of four $100 \mathrm{ml}$ volumetric flasks containing $25 \mathrm{ml}$ of deionized water and was allowed to swell for $45 \mathrm{~min}$. Two-hundred and fifty milligrams of risperidone was accurately weighed and was added with further addition of $25 \mathrm{ml}$ of deionized water and was stirred for $0.5 \mathrm{~h}, 1 \mathrm{~h}, 1.5 \mathrm{~h}$ and $2 \mathrm{~h}$, respectively, at room temperature $\left(22^{\circ} \mathrm{C}\right)$ on a mechanical shaker to allow maximum possible loading. Further steps have been carried out similarly as mentioned under heading 'Effect of risperidone resin ratio on drug loading.' Similar procedure was followed at $50^{\circ} \mathrm{C}$ and $80^{\circ} \mathrm{C}$.

Evaluation of Molecular Properties of Drug Resin Complex. Evaluation by X-Ray Diffractometry The Powder XRD patterns of risperidone, Amberlite IRP64 resin, physical mixture of risperidone and resin (1:4 ratio) and risperidone resinate were recorded using Philips XPERT-PRO X-Ray diffractometer having $X$ 'Celerator Detector. Samples were irradiated with monochromatized $\mathrm{Cu} K \alpha$ radiation $(1.5406 \AA)$ after passing through Nickel filters and were analyzed between $40^{\circ}$ and $2^{\circ}(2 \theta)$ with scan step size 0.0167 in spinning condition and number of scan steps was 2274 . The voltage and current applied were $45 \mathrm{kV}$ and $40 \mathrm{~mA}$, respectively.

Evaluation by Differential Scanning Calorimetry The thermal behavior of risperidone, Amberlite IRP64 resin, physical mixture of risperidone and resin (1:4 ratio) and risperidone resinate was determined by using DSC model-Q 1000 of TA Instruments, Delaware (U.S.A.) equipped with an intracooler and a refrigerated cooling system. Indium standard was used to calibrate the DSC temperature. Each sample was placed in an aluminum pan and, then, was crimped with an aluminum cover to provide hermetically sealed samples $(1-2 \mathrm{mg})$. The heating rate was $10^{\circ} \mathrm{C} / \mathrm{min}$. All measurements were performed over $25-300^{\circ} \mathrm{C}$. Nitrogen was purged at $50 \mathrm{ml} / \mathrm{min}$ through cooling unit.

Evaluation by Fourier-Transform Infrared Spectrophotometry Infrared spectra of risperidone, Amberlite IRP64 resin, risperidone resin physical mixture and risperidone resinate were obtained using FT-IR spectrophotometer, Model-Spectrum One of Perkin Elmer Instruments. The pellets were prepared on $\mathrm{KBr}$ press, and the spectra were recorded over the wave number 4000 to $400 \mathrm{~cm}^{-1}$. The four spectra were comparatively evaluated.

In Vitro Taste Masking Evaluation of Resinate USP phosphate buffer of pH 6.8 was prepared. Four milligrams equivalent of risperidone resinate was placed in two $25 \mathrm{ml}$ glass bottles. Five milliliters of the buffer solution was then added and the bottles were allowed to stand for $60 \mathrm{~s}$ and $120 \mathrm{~s}$ respectively. After the specified time, the suspensions were filtered using $0.45 \mu \mathrm{m}$ nylon filters. The filtrates were analyzed for its drug content. The test was performed in triplicates.

Preparation of Risperidone ODT The formulas of the ODT preparation are shown in Table 1. The batch size taken was 1000 tablets. The drug/resinate and the excipients except lubricants were sieved through \#60 ASTM mesh and color was passed through 100\# ASTM mesh separately. The drug was then mixed with diluent (Pearlitol SD200) by geometric mixing in a polybag for $5 \mathrm{~min}$ followed by geometrical mixing of color with it. To the above mixture, superdisintegrant (Crospovidone), sweetener (Aspartame) and flavors (strawberry and peppermint and/or Taste masking) were added and again mixed for $5 \mathrm{~min}$. Then lubricants (calcium stearate and colloidal silicon dioxide) were passed through \# 40 ASTM mesh and added to the above blend and mixed for $2 \mathrm{~min}$. The above blend was compressed at desired tablet weight using $6 \mathrm{~mm}$ round standard concave tooling on a eight 
station single rotary compression machine (Cadmach Machinery Co., Pvt. Ltd., Ahmedabad, India) keeping the tabletting speed of $20 \mathrm{rpm}$ and the compression pressure at such a level so as to achieve hardness of $20-30 \mathrm{~N}$.

Evaluation of Orally Disintegrating Tablets Both formulated and marketed tablets were evaluated for diameter, thickness, weight variation, hardness test, friability, drug content uniformity as per the USP method of tablet evaluation and the observations are shown in Table 1. As per the European Pharmacopoeia the Orodispersible tablets should disintegrate within 3 min. $^{20)}$ In vitro dissolution studies were also performed.

Dissolution Test and Drug Content Uniformity Dissolution studies were carried out on six units using USP Dissolution Apparatus II using $500 \mathrm{ml}$ of $0.1 \mathrm{~N} \mathrm{HCl}$ as dissolution medium at $50 \mathrm{rpm}$ and $37 \pm 0.5^{\circ} \mathrm{C}$. Two milliliters of aliquots were withdrawn at predetermined intervals $(3,5,10$, $15,20,30 \mathrm{~min}$ ) without replacement and were filtered using $0.45 \mu \mathrm{m}$ nylon filter and finally analyzed by high performance liquid chromatography (HPLC) at $238 \mathrm{~nm}$. The replacement was not done as sink condition was sufficiently maintained because of low dose and high solubility of drug in acidic medium and to avoid errors due to short sampling intervals.

For drug content uniformity, 10 intact tablets (each equivalent to $4 \mathrm{mg}$ of risperidone) were transferred individually into 10 dry $100 \mathrm{ml}$ volumetric flasks. Fifty milliliters of $0.1 \mathrm{~N} \mathrm{HCl}$ was added and was sonicated in an ultrasonic water bath for $30 \mathrm{~min}$ while swirling occasionally. Then it was allowed to cool to room temperature. Volume was made up to the mark with $0.1 \mathrm{~N}$ $\mathrm{HCl}$. Twenty milliliters of the above solution was centrifuged and $5 \mathrm{ml}$ of it was diluted to $100 \mathrm{ml}$ with mobile phase and was finally analyzed by HPLC at $238 \mathrm{~nm}$.

To prepare standard solution, $20 \mathrm{mg}$ of the risperidone working standard was accurately weighed and put into a $100 \mathrm{ml}$ dry volumetric flask, $5 \mathrm{ml}$ of acetonitrile was added, it was sonicated to dissolve and volume was made up to the mark with water. Two milliliters of the above solution was diluted to $200 \mathrm{ml}$ with mobile phase and injected.

The system set up was as follows: mobile phase: buffer 6.8 : acetonitrile $(65: 35)$, inertsil $\mathrm{C} 18150 \times 4.6 \mathrm{~mm}$ column, $10 \mathrm{~min}$ run time, $1.0 \mathrm{ml} / \mathrm{min}$ flow rate, $6 \mathrm{~min}$ retention time, $10 \mu \mathrm{l}$ injection volume and wavelength of $238 \mathrm{~nm}$. The evaluation was based on the integration of the area of the risperidone peak. The column was first equilibrated with the mobile phase. The standard solution was injected six times followed by the sample solutions under similar conditions with an injection of intermediate standard solution at the end of every six sample injections. The coefficient of variations of the areas from the active ingredients peaks of the six injections was less than $2.0 \%$ and the coefficient of variation for reference solution injected after every six injections of sample solutions was less than $3.0 \%$.

In Vivo Taste Evaluation of Resinate and ODT Taste evaluation of the

Table 1. Batches of Risperidone Mouth Dissolving Tablets Prepared by Direct Compression and Comparison of Physical Parameters with Marketed Product

\begin{tabular}{|c|c|c|c|}
\hline Ingredients & Batch I & Batch II & $\begin{array}{l}\text { Marketed } \\
\text { product }\end{array}$ \\
\hline Risperidone API & 4.0 & - & - \\
\hline Risperidone resinate & - & 21.00 & \\
\hline Pearlitol SD 200 & 62.226 & 45.394 & \\
\hline Polyplasdone XL10 & 12.6 & 12.6 & \\
\hline Aspartame & 0.84 & 0.84 & \\
\hline Calcium stearate & 3.36 & 3.36 & \\
\hline Aerosil & 0.84 & 0.84 & \\
\hline Taste masking flavor & 0.168 & - & \\
\hline Strawberry flavor & 0.504 & 0.504 & \\
\hline Peppermint flavor & 0.42 & 0.42 & \\
\hline Red iron oxide & 0.042 & 0.042 & \\
\hline Tablet weight & $85.0 \pm 1.02$ & $85.0 \pm 0.92$ & - \\
\hline Diameter (mm) & $6.01 \pm 0.02$ & $6.01 \pm 0.04$ & - \\
\hline Thickness (mm) & $3.00 \pm 0.07$ & $3.02 \pm 0.05$ & - \\
\hline Hardness $(\mathrm{N})$ & $25 \pm 5$ & $25 \pm 5$ & Very soft \\
\hline DT in apparatus (s) & $12 \pm 4$ & $11 \pm 3$ & $3 \pm 2$ \\
\hline DT in mouth (s) & $22 \pm 4$ & $20 \pm 5$ & $5 \pm 3$ \\
\hline Friability $(\%)$ & 0.179 & 0.072 & - \\
\hline $\begin{array}{l}\text { Drug content uniformity } \\
\quad(\%)\end{array}$ & $100.6 \pm 1.6$ & $100.98 \pm 0.96$ & $99.45 \pm 0.03$ \\
\hline
\end{tabular}

I, taste masking with flavors; II, addition of drug in the form of resinate for taste masking. drug resin complex was performed by consensus of trained taste panel of six healthy volunteers in the age groups of 20 to 30 years. The drug, drug resin complex equivalent to $4 \mathrm{mg}$ risperidone and risperidone ODT with resinate and without resinate and marketed product was held in mouth for $60 \mathrm{~s}$ by each volunteer, and the bitterness level was recorded against pure drug using a numerical scale. ${ }^{21)}$ In case of ODT, disintegration time was also noted. After $60 \mathrm{~s}$, the disintegrated tablet was spitted out and the mouth was rinsed thoroughly with mineral water. A numerical scale was used with the following values: $0=$ tasteless, $0.5=$ aftertaste, $1.0=$ slight, $1.5=$ slight to moderate, $2.0=$ moderate, $2.5=$ moderate to strong, $3=$ strong and $3+=$ very strong. ${ }^{3)}$

Stability Study ODT of Batch I and II, without and with resin, respectively, were packed in $30 \mathrm{cc}$ HDPE bottles, sealed and kept at $40^{\circ} \mathrm{C}$ and $75 \%$ relative humidity in stablity chamber (Narang Scietific Works Pvt. Ltd., New Delhi, India) for a period of 3 months as per ICH guidelines. Samples withdrawn at 1, 2 and 3 months were analysed for drug content, hardness, disintegration time and dissolution test.

\section{Results}

Effect of Risperidone Resin Ratio on Drug Loading Batches were fabricated with different ratios of drug to resin $(\mathrm{w} / \mathrm{w})$ ranging from $1: 1$ to $1: 8$ in aqueous medium and it was observed that there was a sharp increase in loading efficiency with increase in the ratio from $1: 1$ to $1: 4$ i.e. from 92.12 to $99.72 \%$. Increase in ratio from $1: 5$ to $1: 8$ showed no significant increase in the loading as can be seen from Fig. 1.

Effect of $\mathbf{p H}$ for Risperidone Resinate Formation Buffer solutions of different $\mathrm{pH}$ ranging from 4.0 to 8.0 were prepared as per USP specifications and batch equilibration was carried out at 1:4 risperidone to resin ratio. The results are shown in Fig. 2.

Effect of Medium on Loading Efficiency and Time of Complexation Two different complexation media were se-

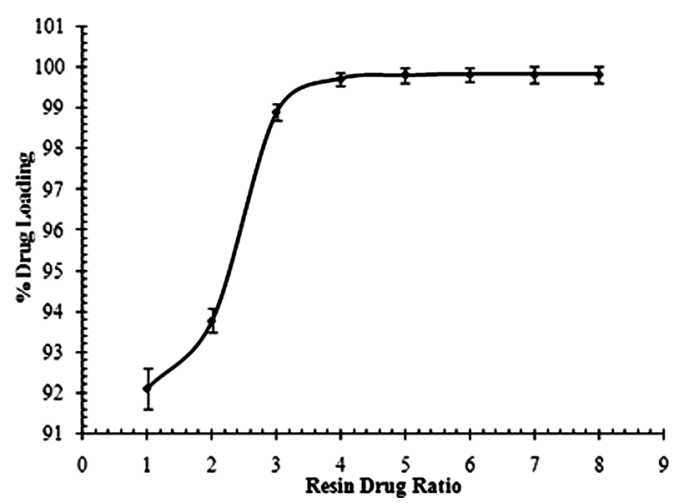

Fig. 1. Effect of Ratio of Risperidone to Amberlite IRP-64 Resin

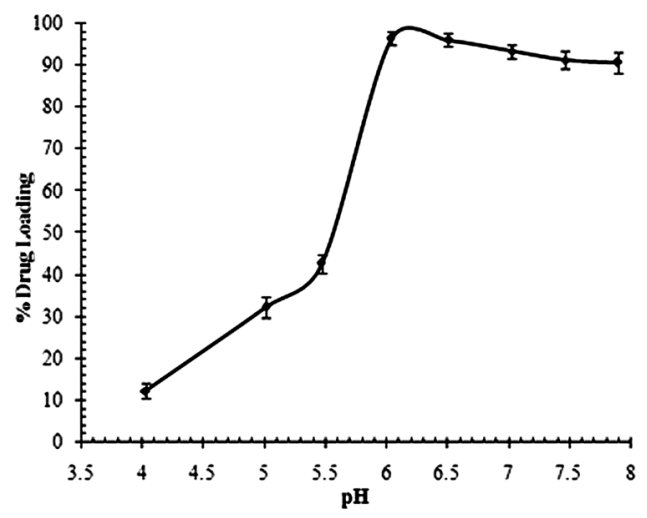

Fig. 2. Effect of $\mathrm{pH}$ on Resinate Formation 
lected, one with water alone while the other using a combination of water and ethanol $(1: 1)$, and the effect of the medium on drug loading efficiency and time of complexation was studied. No significant improvement in loading efficiency by using aqueous alcoholic medium as compared to aqueous medium $(99.69 \%$ in aqueous and $99.75 \%$ in hydroalcoholic medium) was observed when allowed to equiliberate for $48 \mathrm{~h}$. However, time of complexation reduced significantly in case of hydroalcoholic medium as compared to aqueous medium as shown in Fig. 3.

Effect of Temperature on Loading Efficiency Drug loading on Amberlite IRP64 resin was studied in the temperature range of 22 to $80^{\circ} \mathrm{C}$ in deionized water (Fig. 4). The drug loading at the temperatures i.e. $22^{\circ} \mathrm{C}, 50^{\circ} \mathrm{C}$ and $80^{\circ} \mathrm{C}$ were about $99.25 \%, 99.39 \%$ and $99.41 \%$, respectively, in $2 \mathrm{~h}$.

Molecular Properties of Drug-Resin Complexes. XRay Diffractometry Evaluation The comparative X-ray pattern of diffraction (XRPD) of risperidone, Amberlite IRP64 resin, physical dispersion of drug and resin and drug resin complex (DRC) is shown in Fig. 5. The XRPD of pure drug has a number of sharp peaks, while the resin showed a diffused peak or hollow pattern. The XRPD of the physical dispersion of drug and resin shows a sum of several sharp peaks owing to the crystal nature of risperidone and some

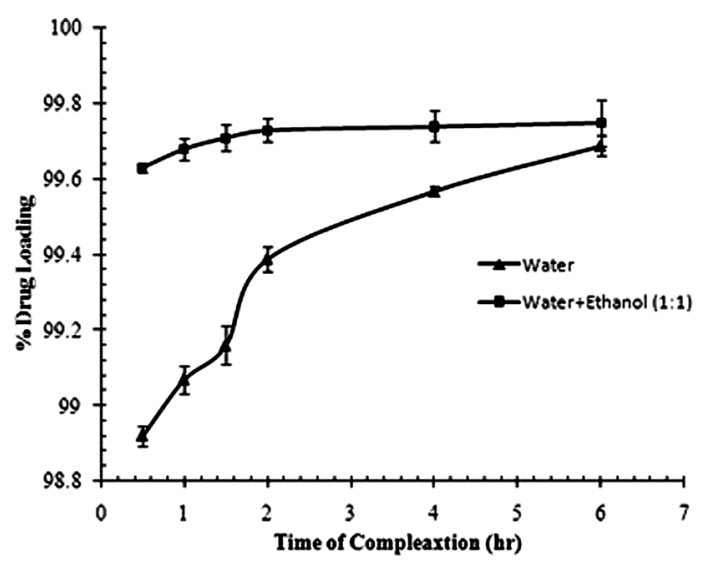

Fig. 3. Effect of Type of Medium on Time of Complexation diffused peaks of the amorphous resin. The molecular state of the drug prepared as DRC shows a hollow diffused pattern and the absence of drug peaks.

Differential Scanning Colorimetric Evaluation Thermal behavior of risperidone, IRP64 resin, risperidone resinate, and risperidone resin physical mixture was studied by DSC analysis and their thermographs are shown in Fig. 6. The DSC curve of the pure drug shows a sharp endothermic peak at $170.29^{\circ} \mathrm{C}$ and shows a small gradual exotherm at $210^{\circ} \mathrm{C}$ indicating onset (endothermic-exothermic inversion) and gradual decomposition. The DSC curve of IRP64 shows fractional loss of water between $80^{\circ} \mathrm{C}$ and $140{ }^{\circ} \mathrm{C}$ and another endotherm at $235.63^{\circ} \mathrm{C}$ to indicate resin melting. The DSC curve of physical mixture of risperidone and amberlite resin shows the sum of endotherms of both drug as well as resin. While thermal behavior of risperidone resinate shows fractional loss of water between $80^{\circ} \mathrm{C}$ and $140^{\circ} \mathrm{C}$ and another endotherm at $217.74^{\circ} \mathrm{C}$ indicating formation of resinate.

Fourier-Transform Infrared Spectrophotometric Evaluation The comparative infrared spectra of risperidone, IRP64 resin, physical dispersion of drug and resin and drug resin complex (DRC) are depicted in Fig. 7. Risperidone spectrum shows a prominent peak at $3058.1 \mathrm{~cm}^{-1}$ corresponding to the aromatic C-H stretching and at $2941.7 \mathrm{~cm}^{-1}$ and

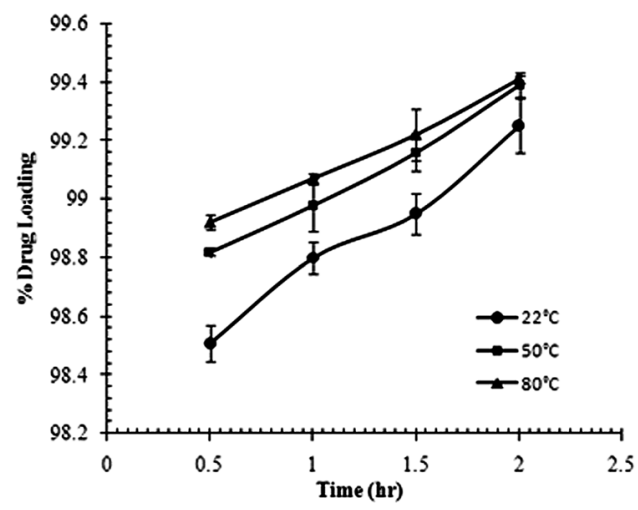

Fig. 4. Effect of Temperature on Drug Loading Efficiency

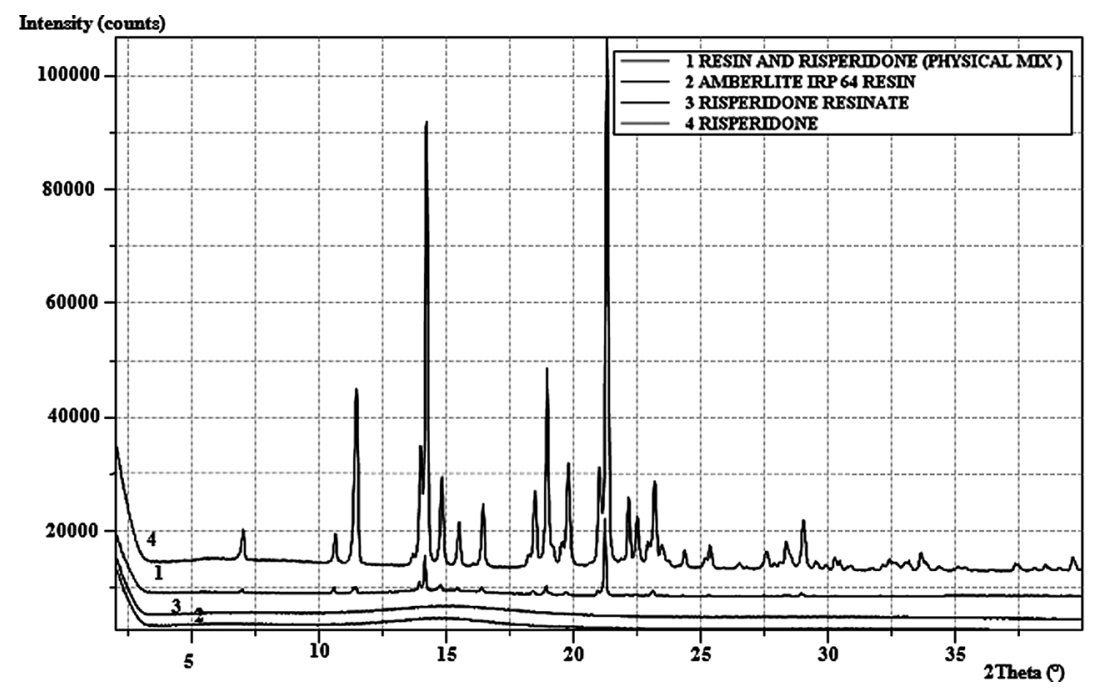

Fig. 5. Comparison of X-Ray Diffractograph of Risperidone, Amberlite IRP64 Resin, Their Physical Mixture and Risperidone Resinate (1:4 Weight Ratio) 


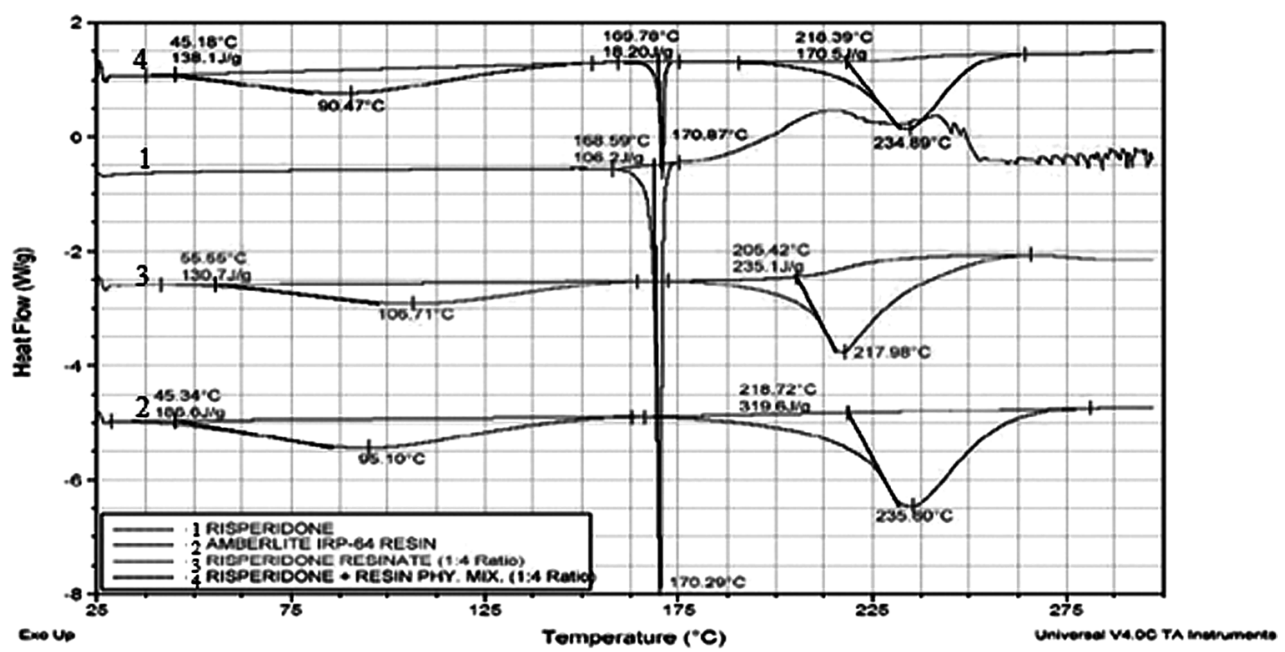

Fig. 6. The Comparative Differential Scanning Calorimetric Thermographs of Risperidone API, Amberlite IRP64 Resin, Risperidone Resinate and Risperidone Resin Physical Mixture (1:4 Weight Ratios)

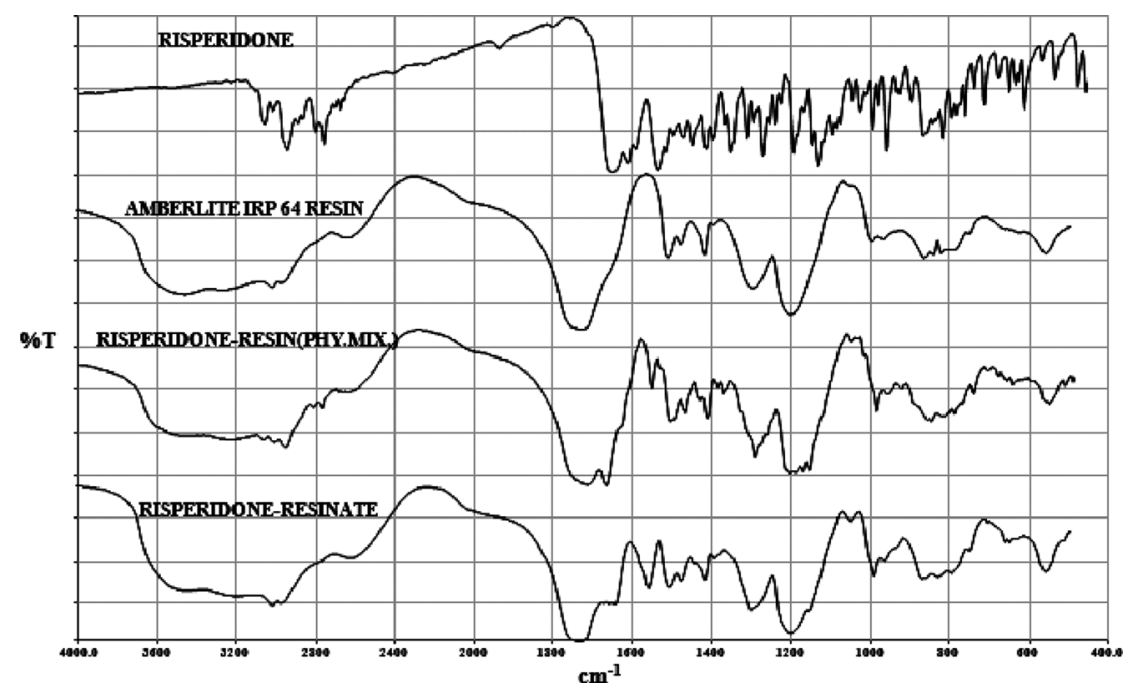

Fig. 7. Comparative Diagram of FT-IR Spectra of Risperidone API, Amberlite IRP64 Resin, Risperidone Resinate and Risperidone Resin Physical Mixture (1:4 Weight Ratio)

$2757.1 \mathrm{~cm}^{-1}$ due to aliphatic $\mathrm{C}-\mathrm{H}$ stretching. A prominent peak at $1651.6 \mathrm{~cm}^{-1}$ corresponds to $\mathrm{C}=\mathrm{O}$ stretching of aryl acids and peaks at $1535.2 \mathrm{~cm}^{-1}$ and $1448.2 \mathrm{~cm}^{-1}$ corresponds to $\mathrm{C}=\mathrm{C}$ and $\mathrm{C}=\mathrm{N}$ stretching. Peak at $1412.9 \mathrm{~cm}^{-1}$ is due to aliphatic $\mathrm{C}-\mathrm{H}$ bending and peaks at 958.7, 866.5 and $817.6 \mathrm{~cm}^{-1}$ are due to aromatic $\mathrm{C}-\mathrm{H}$ bending. Other peaks at $1351.5 \mathrm{~cm}^{-1}$ and $1130.7 \mathrm{~cm}^{-1}$ corresponds to $\mathrm{C}-\mathrm{N}$ stretching and $\mathrm{C}-\mathrm{F}$ stretching respectively.

IRP64 resin shows characteristic peaks at $1700.1 \mathrm{~cm}^{-1}$ corresponding to $-\mathrm{C}=\mathrm{O}$ stretching. A peak at $3444.9 \mathrm{~cm}^{-1}$ is due to $-\mathrm{OH}$ stretching, which lies in standard range of 3400 to $3600 \mathrm{~cm}^{-1}$. Presence of peak in range of $900-670 \mathrm{~cm}^{-1}$ i.e. at $786 \mathrm{~cm}^{-1}$ is due to aromatic $\mathrm{C}-\mathrm{H}$ bending (out of plane) and at $827 \mathrm{~cm}^{-1}$ is due to 1,4-disubstitution (para) of phenyl ring. Simple $\mathrm{C}-\mathrm{H}$ stretching vibrations for saturated aliphatic species occur between 3000 and $2800 \mathrm{~cm}^{-1}$ and the corresponding simple bending vibrations normally occur between 1500 and $1300 \mathrm{~cm}^{-1}$ as here it is at $2996.9 \mathrm{~cm}^{-1}$ and $1451.6 \mathrm{~cm}^{-1}$ respectively.

It was seen that the IR spectrum of physical dispersion of risperidone and Amberlite IRP64 resin showed superimposi-
Table 2. Quantitative in Vitro Taste Masking Evaluation of Resinate of Risperidone

\begin{tabular}{lrccc}
\hline \hline Risperidone & $\begin{array}{c}\text { Time } \\
\text { resinate with }\end{array}$ & $\begin{array}{c}\text { Concentration } \\
\text { in } 5 \mathrm{ml} \text { pH 6.8 } \\
\text { phosphate buffer } \\
(\mu \mathrm{g} / \mathrm{ml})\end{array}$ & $\begin{array}{c}\text { Amount of free } \\
\text { drug in 5 ml } \\
\mathrm{pH} \mathrm{6.8} \mathrm{buffer} \\
(\mathrm{mg})\end{array}$ & $\begin{array}{c}\text { \% Drug } \\
\text { release }\end{array}$ \\
\hline Amberlite & 60 & $16.34 \pm 1.2$ & $0.08 \pm 0.006$ & $2.00 \pm 0.15$ \\
IRP64 & 120 & $20.12 \pm 2.5$ & $0.10 \pm 0.013$ & $2.50 \pm 0.33$ \\
\hline
\end{tabular}

tion of the drug and resin spectra. The IR spectrum of resinate is similar to that of IRP 64 resin except the absence of peak at $3444.9 \mathrm{~cm}^{-1}$ in drug resinate $1: 4$ ratio.

Taste Masking Evaluation and Drug Release in Gastric pH Drug release study in $5 \mathrm{ml}$ of $\mathrm{pH} 6.8$ phosphate buffer was used to study the taste masking efficiency of the resinate. It was found that $2.5 \%(20.12 \mu \mathrm{g} / \mathrm{ml})$ of the drug was released in $120 \mathrm{~s}$ (Table 2).

In vitro dissolution study of ODT containing the resinate, in $500 \mathrm{ml}$ of $0.1 \mathrm{~N} \mathrm{HCl}$ showed about $92 \%$ of drug release 
Table 3. Bitterness Evaluation by Taste Panel

\begin{tabular}{|c|c|c|c|c|c|c|}
\hline \multirow{2}{*}{ Samples } & \multicolumn{6}{|c|}{ Volunteers } \\
\hline & I & II & III & IV & $\mathrm{V}$ & VI \\
\hline Risperidone & $3+$ & $3+$ & $3+$ & $3+$ & $3+$ & $3+$ \\
\hline Risperidone resinate & 0 & 0 & 0 & 1.0 & 0 & 0.5 \\
\hline ODT (taste mask flavor) & 1.5 & 2.0 & 2.0 & 1.5 & 2.5 & 1.5 \\
\hline ODT (resinate) & 0 & 0 & 0 & 0.5 & 0 & 0.5 \\
\hline Marketed product & 0 & 0 & 0 & 0 & 0 & 0.5 \\
\hline
\end{tabular}

$0=$ tasteless, $0.5=$ aftertaste, $1.0=$ slight, $1.5=$ slight to moderate, $2.0=$ moderate, $2.5=$ moderate to strong, $3=$ strong and $3+=$ very strong.

Table 4. Stability Study Data of Batches I and II in Accelerated Stability Conditions

$40^{\circ} \mathrm{C}$ and $75 \%$ relative humidity

\begin{tabular}{|c|c|c|c|c|c|c|}
\hline \multirow[t]{2}{*}{ Samples } & \multicolumn{3}{|c|}{ Batch I } & \multicolumn{3}{|c|}{ Batch II } \\
\hline & $1 \mathrm{M}$ & $2 \mathrm{M}$ & $3 \mathrm{M}$ & $1 \mathrm{M}$ & $2 \mathrm{M}$ & $3 \mathrm{M}$ \\
\hline Drug content $(\%)$ & $100.5 \pm 1.6$ & $100.0 \pm 1.2$ & $99.8 \pm 0.7$ & $100.8 \pm 0.9$ & $100.2 \pm 0.8$ & $99.6 \pm 0.6$ \\
\hline Disintegration time (s) in DT apparatus & $12 \pm 2$ & $11 \pm 3$ & $10 \pm 2$ & $10 \pm 2$ & $12 \pm 4$ & $13 \pm 3$ \\
\hline Hardness (N) & $23 \pm 3$ & $24 \pm 1$ & $22 \pm 3$ & $24 \pm 3$ & $25 \pm 4$ & $26 \pm 4$ \\
\hline Dissolution test (30 min) & $99.8 \pm 2.0$ & $97.9 \pm 0.8$ & $98.8 \pm 1.9$ & $97.9 \pm 1.5$ & $97.2 \pm 1.2$ & $98.5 \pm 2.1$ \\
\hline
\end{tabular}

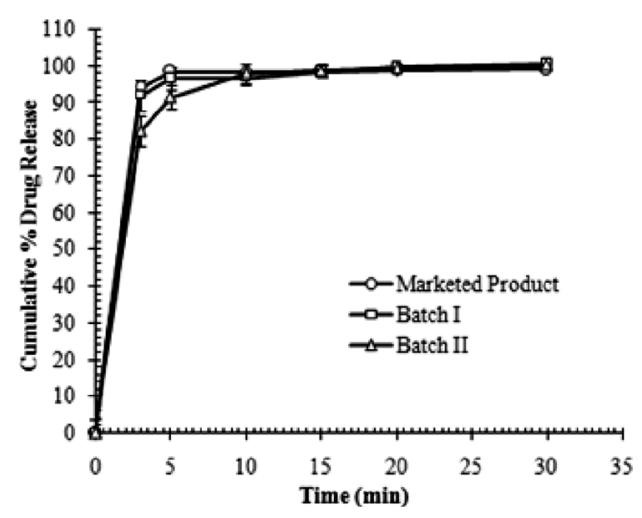

Fig. 8. Comparative Dissolution Profiles of Marketed Product and Batches I and II

from the complex within $5 \mathrm{~min}$. The drug release profile completely matches with that of marketed product (Fig. 8).

Physical Parameters of ODT The fabricated ODTs were tested for their physical parameters viz. diameter, thickness, hardness, weight variation, disintegration time and friability. The results are tabulated in Table 1 .

Stability Study The results of the stability study are compiled in Table 4. No significant changes were observed in the drug content, hardness, disintegration time and dissolution data.

\section{Discussion}

Choice of Resin for Taste Masking of Bitter Taste of Risperidone The basis of selection of IER for drug delivery applications is ruled by its functional-group characteristics. $^{22)}$ The drug being a free base, a weak acid CE resin is required for the purpose of taste making. From the different variety of the $\mathrm{CE}$ resins available in the market, Amberlite, a reputed brand of resin of Rohm and Haas Company was used. Amberlite resin grade IRP-88 and Amberlite resin grade IRP-64 are the taste masking grades of the resin, being weakly acidic, will release the drug immediately after coming in contact with acidic $\mathrm{pH}$.

Amberlite resin grade IRP-88, a cationic (weakly acidic) ion-exchange resin uses the potassium ion as the exchange cation which requires that a weakly basic active substance such as risperidone be converted into a water soluble acid salt, such as the hydrochloric acid salt. The cationic (weakly acidic) ion-exchange resin Amberlite resin grade IRP-64 (polacrilex resin; hereinafter generally referred to as IRP-64) uses the hydrogen ion as the exchange ion. So, it can easily adsorb drug in its base form. ${ }^{16}$ ) The high affinity of IRP64 resin for the hydrogen ion results in ready desorption of drug of adsorbed species by exposure to an acidic environment such as that exhibited in the stomach. In an acidic aqueous medium, the IRP-64 resin is in a nonionic state and exists as the free acid. Therefore, adsorption (loading) onto this cation resin is carried out at higher $\mathrm{pH}$. Since the physiochemical properties of this grade were found to be best suited for the needs of the present formulation strategy, therefore grade IRP-64 was finalized.

Factors and Process Affecting Risperidone Resinate Formation Amount of drug loaded on the resin is influenced by factors such as: inherent affinity or selectivity between the ion exchange resin and the drug, concentration of the drug in the loading solution, concentration and selectivity of the competing cations and $\mathrm{pH}$ of the loading solution.

The first factor indicated above is related to the physicochemical properties of the drug. However risperidone, being a weakly basic and ionizable drug, is expected to have good affinity for this cation exchange resin. Moreover, it has been reported that drugs containing a tertiary amino group give much higher selectivity coefficients than those with primary, secondary, or quaternary amines. ${ }^{23)}$ Thus, taste masking of risperidone should be more efficient being a tertiary amine drug. The other factors can be evaluated to achieve the maximum drug loading efficiency.

Particle size of Amberlite IRP64 resin, less than $150 \mu \mathrm{m}$ 
as per the supplier's specifications, is suitable for taste masking. With particles of diameter below $50 \mu \mathrm{m}$, processing of the discrete particles is difficult due to dusting, poor flowability, slow flow-through rate and other mechanical difficulties associated with small particles. Particles of a diameter above this range create an uncomfortable mouth feel.

Effect of Risperidone Resin Ratio on Drug Loading The phenomenon of the increase in drug load with the increase in the resin content was due to the increase in the interaction between the drug molecules and the resin particles.

In aqueous medium at neutral $\mathrm{pH}$, increasing the ratio of resin to active substance resulted in decrease in solution concentration of the active substance because more resin was available to adsorb the active substance from solution. $\mathrm{pH}$ of the aqueous medium also decreased due to increase in concentration of hydrogen ions in solution as a result of an increased amount of available resin, resulting in protonation of more of the active substance and its adsorption on resin. Therefore, it can be concluded that shifting the aqueous medium $\mathrm{pH}$ or the ratio of resin to active substance, can affect the efficiency of complexation.

Since, the increase in loading efficiency of the drug is negligible after $1: 4$ ratio $(0.08 \%$ increment on increasing ratio from $1: 4$ to $1: 5$ ), increasing the resin amount for a negligible increase in drug loading is not economically justifiable. Therefore, drug : resin ratio of $1: 4$, was selected for further investigation.

Effect of $\mathbf{p H}$ for Risperidone Resinate Formation At $\mathrm{pH} \mathrm{4}$, the drug loading efficiency was minimum (ca. $12.22 \%$ ). This is because being a cation exchange resin; IRP64 is available as unionized free acid in an acidic aqueous medium. ${ }^{19)}$ On increasing the $\mathrm{pH}$ from 4 to 6 , a steep increase in drug loading efficiency was observed $(\mathrm{pH} 5$ : $32.25 \%$, pH 5.5: $42.54 \%$ and $\mathrm{pH}$ 6: $96.35 \%$ ) as shown in Fig. 2. Above $\mathrm{pH} 4$, the IRP-64 resin's carboxyl groups liberate hydrogen ions resulting in protonation of a weakly basic active substance which binds to the resin's anionic carboxylic group by an ionic bond to form a water-insoluble complex. As the $\mathrm{pH}$ is increased to 6.0, a greater quantity of drug substance is solubilized and the equilibrium concentration of the drug substance shifts to complex the solubilized active substance with the resin. On increasing the $\mathrm{pH}$ above 6.0, a slight decrease in the loading efficiency was observed. This can be explained on the basis of the $\mathrm{p} K_{\mathrm{a}}$ of the drug of 7.91. At a $\mathrm{pH}$ higher than the $\mathrm{p} K_{\mathrm{a}}$ of the drug, the drug remains mostly in the nonionized form. At $\mathrm{pH}$ 6.0, both the drug and the resin are ionized in sufficient quantity, which is highly favorable for their interaction to take place, resulting in maximum resinate formation.

However, the maximum loading achieved using $\mathrm{pH} 6.0$ phosphate buffer as complexation medium was $96.35 \%$, as compared to $99.72 \%$ which was achieved by using deionized water as medium. This is because of the presence of cations $\left(\mathrm{Na}^{+}\right.$and $\left.\mathrm{K}^{+}\right)$present in the phosphate buffer medium, which compete with the drug for the binding site on the resin.

If deionized water $(\mathrm{pH} \mathrm{7)}$ is used as the complexation medium and the resin is added to it and allowed to swell for $45 \mathrm{~min}$, then the $\mathrm{pH}$ of the slurry shifts to acidic side, i.e., $4-4.5$. However, there is no necessity to adjust the $\mathrm{pH}$ to 6.0 , because after the addition of the drug, which is basic in nature, the $\mathrm{pH}$ of the suspension again becomes $6.0-6.11$ (only if risperidone resin ratio is $1: 4$ ). If $\mathrm{pH}$ adjustment is made, it results in slight decrease in loading efficiency due to the incorporation of the competing cations present in the $\mathrm{pH}$ adjusting solution.

Effect of Medium on Loading Efficiency and Time of Complexation Ethanol was used in this study to enhance the solubility of the drug, which may increase the loading efficiency or accelerate complexation rate. The results showed that there was no significant improvement in loading efficiency by using aqueous alcoholic medium as compared to aqueous medium (99.69\% in aqueous and $99.75 \%$ in hydroalcoholic medium). This shows that the loading efficiency depends mainly on the $\mathrm{pH}$ and the ratio and the presence of competing ions in the media rather than on medium of complexation.

However, there was marked decrease in the complexation time in the aqueous alcoholic medium (Fig. 3). Although the drug is practically insoluble in water, but in a particular volume of water some amount of the drug will be in solution form that will get loaded to resin and more amount of drug from insoluble particles of drug will enter into the solution and this equilibrium shift will continue till a sufficient amount of drug gets loaded on the resin. On the other hand, in case of aqueous alcoholic solution as the complexation medium, the drug is solubilized markedly due to the presence of ethanol (risperidone is sparingly soluble in ethanol) and greater amount of the drug in solution is available for loading, completing the entire reaction in a shorter duration of time. Thus, using an aqueous alcoholic medium in the resinate formation will significantly reduce the process time. Though the small increment in the drug loading efficiency with change in the medium of complexation may not be meaningful at the laboratory scale, it may be valuable in large scale production by significantly reducing the loss of drug and by saving process time.

Effect of Temperature on Loading Efficiency It was found that the drug loading was quite efficient at all the three temperatures i.e. $22^{\circ} \mathrm{C}, 50^{\circ} \mathrm{C}$ and $80^{\circ} \mathrm{C}$ with about $99.00-$ $99.50 \%$ drug loading efficiency at the lowest temperature of investigation. However, the slight increment in the loading efficiency with increase in temperature may be due to increased ionization of drug and resin at higher temperature.

Molecular Properties of Drug-Resin Complexes. XRay Diffractometry Evaluation The XRD pattern of resinate confirms that the entrapped drug is dispersed and adsorbed monomolecularly on the resin binding sites and has lost its crystalline nature. Thus, the resinate is amorphous in nature. In the case of physical dispersions of drug and Amberlite IRP64, drug molecules are outside the resin beads, therefore, crystalline sharp peaks appeared in diffractogram.

Differential Scanning Colorimetric Evaluation Absence of endotherms at $170.29^{\circ} \mathrm{C}$ and $235.63^{\circ} \mathrm{C}$ indicates the absence of free drug and resin respectively. The study confirms the complexation of risperidone with IRP64 resin, and the DSC and XRPD results reveal the amorphous nature of drug adsorbates.

Fourier-Transform Infrared Spectrophotometric Evaluation The IR spectrum of physical mixture of risperidone and resin was a superimposition of IR spectra of resin and drug depicting that there was no appreciable interaction be- 
tween the drug and resin in these mixtures, coinciding with the results from DSC and XRPD.

The absence of peak at $3444.9 \mathrm{~cm}^{-1}$ in drug resinate, which was due to $-\mathrm{OH}$ stretching of resin signifies that during resinate formation there was interaction of the amino group of drug with the carboxylic group of Amberlite IRP64 resin.

Taste Masking Evaluation and Drug Release in Gastric pH The conventional in-vitro method of dissolution study lacks relevance to simulate the behavior of an ODT in the buccal cavity, due to excessive large dissolution media volume. Therefore, a more relevant method was developed in our laboratory wherein the drug release in $5 \mathrm{ml}$ of $\mathrm{pH} 6.8$ phosphate buffer (to simulate salivary $\mathrm{pH}$ and volume approximately) ${ }^{24)}$ was analyzed to evaluate the taste masking efficiency of the resinate. It was found that $2.5 \%$ of the drug was released in $120 \mathrm{~s}$ (Table 2). However, the threshold concentration of risperidone to impart bitterness is $25 \mu \mathrm{g} / \mathrm{ml},{ }^{16}$ ) while in case of risperidone resinate, the released drug concentration is $20.12 \mu \mathrm{g} / \mathrm{ml}$ in $120 \mathrm{~s}$. The amount of drug released would further decrease as the disintegration time of the ODT is less than $20 \mathrm{~s}$, which would be insufficient to impart bitter taste. The presence of exchangeable ions of ionizable electrolytes in the salivary fluid may be responsible for this release. The exchange process of drug release follows the following equation.

$\operatorname{resin}^{-}-\operatorname{drug}^{+}+\mathrm{X}^{+}=\operatorname{resin}^{-}+\operatorname{drug}^{+}-\mathrm{X}^{+}$

Where, $\mathrm{X}^{+}$represents the ion in the GI tract.

Particle diffusion and film diffusion are sequential steps in drug release by ion exchange process. ${ }^{25)}$ Electrostatic interaction governs the equilibrium distribution of the drug species between the resin and solution phases. ${ }^{26-28)}$ The drug resinate is stable in salivary $\mathrm{pH}$ during its disintegration in the oral cavity. Taste masking evaluation by volunteers also indicated that the resinate formation was an efficient method of taste masking for this drug (Table 3). The ODT prepared using resinate showed better acceptability than ODT without resinate. The combination of pleasant tasting flavors for better mouthfeel and taste masked resinate attributes to better palatability of the ODT.

About $92 \%$ of drug was released from the complex contained in ODT within $5 \mathrm{~min}$ in $500 \mathrm{ml}$ of $0.1 \mathrm{~N} \mathrm{HCl}$ indicating that though the resinate would remain intact in the buccal cavity, the drug would be released completely in gastric condition. The drug release profile completely matches with that of marketed product (Fig. 8).

Stability Study As resin has been reported to improve the stability of drugs, ${ }^{29}$ ) therefore, both the batches (I and II) of ODT without and with resin, respectively, were subjected to accelated conditions for a period of three months. Batch without resin was also found to be stable even after 3 months indicating that the resin had no significant role to play in the stability of the product except to mask the taste of the bitter drug.

Cost Effectiveness of the Process and Formulation The marketed product of risperidone (Risperdal ${ }^{\circledR} \mathrm{M}^{\mathrm{T}} \mathrm{TAB}{ }^{\mathrm{TM}}$ Orally Disintegrating Tablets $4 \mathrm{mg}$ ) is a very delicate soft tablet prepared by lyophilization process of drug resin suspension in which drug to resin ratio is $1: 6$ to impart sufficient taste masking. The suspension is lyophilized in blister leading to formation of very porous fast disintegrating drug matrix which is highly fragile and moisture sensitive. ${ }^{16)}$ Alu alu blister pack with special peel off cover is used to avoid breakage of the tablets during handling and storage. The entire process of fabrication and packaging of the delicate lyophilized product requires elaborate equipments and packaging materials. However, in the present investigation, the tablets are prepared by conventional direct compression method where the drug resin ratio is $1: 4$ instead of $1: 6$, as the unloaded drug is washed out and solvent is incorporated to enhance drug loading. Drying was done in vacuum oven instead of lyophilizer. Although, a number of methods for the fabrication of ODT are available, direct compression was used, as unlike other methods, this technique is cost effective, can be carried out in a single step using conventional compression machine and yields robust and nonfriable product. ${ }^{30)}$ Tablets prepared have low disintegration time and sufficient strength to withstand its integrity during handling and storage (Table 1). The ODT containing resinate, prepared in this investigation, can be applicable for wide range of packaging. Thus, the whole process requires simple machinery for fabrication and packaging to deliver a product of equivalent quality.

\section{Conclusion}

In the present investigation, a complex of risperidone was successfully formulated using Amberlite IRP64 resin, which was confirmed using FT-IR, XRD and DSC. The volunteers rated the complex and the ODT as tasteless and agreeable. The methods designed for drug resinate complexation and tablet formulation are simple, rapid, cost effective and highly efficient. The ODT fabricated were found to be stable for a period of 3 months when tested under accelerated stability conditions.

Acknowledgements The authors are grateful to University Grants Commission, New Delhi, India for the financial assistance for the present work. The authors are also thankful to Sandoz Pvt. Ltd., Thane, India, for providing facilities to carry out the molecular characterization of the samples.

\section{References}

1) Mantell C. L., "Adsorption,” 2nd ed., McGraw-Hill, New York, 1951, pp. $185-216$

2) Betty W., Michael P., Dokuzovic V., Lam V., U.S. Patent 6001392 (1999).

3) Agarwal R., Mittal R., Singh A., Drug Dev. Ind. Pharm., 26, 773776 (2000).

4) Jenke D. R., Pharm. Res., 6, 96-99 (1989).

5) Irwin W. J., Belaid K. A., Drug Dev. Ind. Pharm., 13, 2017-2031 (1987).

6) Burke G. M., Drug Dev. Ind. Pharm., 12, 713-732 (1986).

7) Plaizier-Vercammen J. A., Int. J. Pharm., 85, 45-50 (1992).

8) Anand V., Kandarapu R., Garg S., Drug Dev. Technol., 6, 905-914 (2001).

9) Hui H., "Controlled Drug Delivery," ed. by Robinson J. R., Lee V. H. L., Marcel Dekker, New York, 1987, pp. 412-414.

10) Nanda A., Kandarapu R., Garg S., Indian J. Pharm. Sci., 64, 10-17 (2002).

11) Gao R., Shao Z. J., Fan A. C. L., Witchey-Lakshmanan L. C., Stewar D. C., U.S. Patent 6514492 (2003).

12) Honeysett R. A., Freely L. C., Hoadley T. H., Sims E. E., Eur. Pat. Appl. EP0501763 (1992).

13) Cotterill J. V., Giovanna M., Cowan D. P., Pest Manag. Sci., 62, 120 125 (2006).

14) Manek S. P., Kamat V. S., Indian J. Pharm. Sci., 43, 209-212 (1981).

15) Lu M. Y., Borodkin S., Woodward L., Li P., Diesner C., Hernandez L., Vadnere M., Pharm. Res., 8, 706-712 (1991). 
16) Gole D., Savall T., Lyou-fu G., Dale W., Paul K., Davies J. D., U.S. Patent Application 20050036977 (2005).

17) Farag Y., Nairn J. G., J. Pharm. Sci., 77, 872-875 (1988).

18) Sanghavi N. M., Indian Drugs, 26, 27-32 (1988).

19) AMBERLITE ${ }^{\mathrm{TM}}$ IRP64, Pharmaceutical grade cation exchange resin: 〈http://www.rohmhaas.com/wcm/products/product_detail.page?product $=1120246 \&$ display-mode $=$ tds\&application $=\rangle$, Rohm and Haas website, 05 July 2008.

20) "European Pharmacopoeia," 4th ed., Supplement 4.2, Tablets, 2002, p. 2435.

21) Borodkin S., Yunker M. H., J. Pharm. Sci., 59, 481-486 (1970).

22) Saunders L., J. Pharm. Pharmacol., 5, 569-578 (1953).

23) Vyas A. H., Bhat C. V., Kamath B. R., Bafna S. L., J. Pharm. Sci., 62,
$1386-1387(1973)$

24) Costa H. O., Neto O. M., Eckley C. A., Dysphagia, 20, 175-181 (2005).

25) Conaghey O. M., Cris J., Corrigan O. I., Int. J. Pharm., 170, 215-224 (1998).

26) Jasari T., Vuorio M., J. Controlled Release, 70, 219-229 (2001).

27) Herrera T., Matejka Z., Eliasek J., Desalination, 48, 161-169 (1983).

28) Liu Z., Cheung R., Wu Y. X., James R., J. Controlled Release, 77, 213-224 (2001).

29) Kankkunen T., Huupponen I., Lahtinen K., Sundell M., Ekman K., Kontturi K., Hirvonen J., Eur. J. Pharm. Sci., 16, 273-280 (2002).

30) Parakh S. R., Gothoskar A. V., Pharm. Technol., 27, 92-100 (2003). 